\title{
Surface Structure and Deep Structure of the Teaching Interaction
}

\author{
Ying Liu ${ }^{1, a}$, Lin Jiang ${ }^{2, b,{ }^{*}}$, Hu Chao ${ }^{3, c}$ and Hongyan Shi ${ }^{4, d}$ \\ ${ }^{1,2,4}$ Aerial Ammunition Department,Air Force Logistics College,P.R.China,210000 \\ ${ }^{3}$ Department of Basic Education, Air Force Logistics College, P.R China,210000 \\ Email:aShy7823@163.com
}

Keywords: Innovation education,Humanity hypothesis, Generative teaching.

Abstract. Like other social activities, interactive teaching is divided into surface structure and deep structure.Surface structure is the teaching process, it is existed between students and teachers can observe, can record the external form of interaction;And the deep structure of interactive teaching is affected, the dominant teaching interaction forms of inherent theoretical framework.Understand the deep structure of interactive teaching, in teaching interaction,teachers are heartfelt love students, fully into teaching, so that the whole life of infiltration in teaching between teachers and students the significance of interactive communication;The pedagogical implication behind the focus on interactive teaching form, the significance of the interactive teaching communicated more rich deep.

\section{Introduction}

According to the theory of structuralism, and all social activities has the points of surface structure and deep structure, interactive teaching is no exception. The present teaching theory research on the surface structure of the teaching interaction is more, and the deep structure to the interaction of teaching is rare.To explore the deep structure of interactive teaching, to the deep understanding of the substance and connotation of the teaching interaction, rich teaching theory in our country, promote the development of teaching reform, has the very vital significance.

\section{The surface structure and deep institutions of teaching interaction}

\subsection{Structuralism on surface structure and deep structure point of view}

Structuralism as a kind of philosophy ideological trend, in France in the 1960 s, and quickly popular in Western Europe and North America countries.Advocates structuralism research method of overall, tense, against local, fracture analysis of "theory of atomic research tendency, the purpose is to explore the social, cultural, is through what kind of relationship between (structure) are expressed.Since F.Saussure "pioneered settlement structure on the surface after looking for the central role of the deep structure of the traditional" [1], through the surface mind, experience and activities, the excavation of the deep, unconscious cultural pattern has become the main direction of structuralism.Structuralism on surface structure and deep structure of the main ideas are: the social activities are a points of surface structure and deep structure;Surface structure is the external form of the deep structure and deep structure is the inner basis of surface structure;Surface structure and deep structure can be mutual conversion.

\subsection{The teaching interactive surface structure and deep structure and other social activities.}

Interactive teaching is divided into the surface structure and deep structure.Teaching interactive surface structure is to point to in the teaching process, occur between students and teachers can observe, can record the external form of interaction. The deep structure of the teaching interaction is affected, dominance inherent theoretical framework in the form of interaction between teachers and students, it decides the connotation and essence of teaching interaction.Teaching interaction of surface structure and deep structure is not teaching interaction between two phases of development, but the two aspects of the process.Like an iceberg metaphor, appeared on the surface of the water is the surface structure of teaching interaction, implicit in the water is under the deep structure of 
interactive teaching. No matter what kind of interactive teaching form (surface structure) they are both controlled by the deep structure of the teaching interaction, and the deep structure of the teaching interaction also rely on certain external interaction forms (surface structure) can be achieved.Teaching interactive surface structure is the form of teaching interaction, it can meet the requirements of teachers and students in the interactive mode, quantity, but can't guarantee the quality of the interaction between teachers and students.

Interactive teaching is the deep structure of teaching, the connotation and essence of directly decides the teaching quality and level of interaction.Even if the teaching interaction in the form of the same, if teachers at different levels for perception of the deep structure teaching interaction, teaching quality and the level of interaction will there is a big difference.Teaching interaction surface structure belongs to the skill level, it provides the rule and pattern of the interaction between the teaching, teachers learn some methods Can be mastered.The meaning of the deep structure of interactive teaching is interactive teaching level, it have a great relationship with the teachers' personal quality, and teachers' experience, understanding is needed to better grasp.

\section{The deep structure of interactive teaching: the significance of communication}

The deep structure of interactive teaching is the meaning of the communication between teachers and students.No matter what form of interactive teaching, its purpose is to realize the significance of communication between students and teachers.In order to better understand the significance of communication, we must first clarify this article said the meaning of "meaning"."Meaning" of the interactive teaching is different from the meaning of "learning" on the level of psychology, also differs from the philosophy of "survival significance", but the integration of these two aspects and formed its own characteristics.

Communicate "meaning" of the interactive teaching based on psychology and philosophy and integrate these two aspects, "education as a kind of science, is based on practice philosophy and psychology, indicate the purpose of the former, the latter pointed out ways and means" [7].From the Angle of the teaching interactive degrees, says the meaning of the communication between teachers and students must include the significance of the psychological level, not just for the experience of sense."Meaning" of teaching interaction is the trinity of cognitive, emotional, mental.The mechanism of psychology, puts forward the meaning of "communication", and focuses on the individual mastery of knowledge process, the ultimate purpose of philosophy points out the meaning of "exchange", and then focus on the value of individual knowledge.And taught to learn the meaning of "exchange" refers to the interaction between students and teachers is how to implement the individual creative possession of knowledge through dialogue, and on the basis of the possession of life experience and the existing value.Psychology level exchange of "meaning" (cognitive and emotional communication) is the basis of the teaching interaction occurs;Communicate the philosophy of "meaning" (spirit) to meet the teaching interaction sublimation to habitat world beyond, ecstasy, make teachers and students feel the harmony of man and the world, the existence significance.Communicate "meaning" of the interactive teaching is not only the thinking process of collision, the emotional communication between teachers and students, but also between teachers and students mental process, experience the meaning of life, is using the individual life experience, teachers and students and teaching material of the spiritual life of dialogue between the process of "horizon fusion".

\subsection{How to grasp the deep structure of teaching interaction}

Different understanding on the part of teaching interaction, leads to teachers' teaching level.Also is interactive teaching, some teachers only mastered the external technical or several patterns of teaching interaction;Some teachers to realize teaching interaction of deep structure and kernel essence, attention to the significance of communication between teachers and students.Although 
master teaching interactive mode and the technology is beneficial to improve teachers' teaching level of interaction, but, after all, teaching is not just a technology, and it is also a way to teachers' and students' way of life and existence.Grasp the deep structure of interactive teaching, is the necessary way of skilled teachers to hr.

\subsection{The teacher's love and commitment}

The deep structure of interactive teaching is the meaning of the communication between teachers and students, thinking collision between teachers and students, emotional and spiritual meet.Pay attention to the teacher exchanges, heartfelt love students, teaching interaction, entire devotion to awaken another heart heart.Teachers love for students will make form "heart towards children survive and grow" pedagogy, infatuation and enjoy into the length of the teachers and students the spirit of life."Teachers love is refers to the heart is always toward children, teacher love form the intention to the highest stage of life and emotional life. Teachers in the teacher's heart of hearts, for to kids' hearts' intention has higher value than 'out of obligation, that is love logic or the logic of the mind."[7] only from the heart the meaning of communication, to reach the depths of the heart.Teachers love of students can make the education career as his life, he will be devoted to teaching interaction, and with his enthusiasm infection and influence students, causing students to the classroom teaching.It is hard to imagine a no enthusiasm and interest of teachers in teaching cause student's study interest and enthusiasm.Teachers only open yourself, may contact with the student have a soul, even if the teaching form of interaction is very rich, also won't have the real significance of communication between teachers and students.

\subsection{Focus on teaching interaction forms the pedagogical implication behind}

Grasp the deep structure of interactive teaching, improve teaching interactive state, for the teacher not only familiar with interactive teaching form, more to understand the pedagogical implication behind the teaching forms, fully understand the teaching interactive significance the cognitive, emotional and spiritual aspects of communication."Education is not only a kind of observable behavior, more important is that it must be an act of education significance of pedagogy, not in that kind of thing can be observed for the, but, like love and friendship, exist in this kind of emotional experience."[8] in addition to the teacher's love and commitment to, the teacher should also enrich their science literacy, to achieve mastery through a comprehensive study of subject knowledge, not only know what it is, also know why, now not only learn knowledge, also understand the context of knowledge;Continuously improve their teaching concept, continuous learning education theory and combined with own education practice experience and reflection, to make learning to infiltrate the teacher did each thing, a way of life to become teachers;Philosophy of quality, at the same time, teachers should have the ultimate meaning of education, the relationship between education and life of reflection and thinking.Teaching is not necessarily become a philosopher, but need to dwell on the problems of the education of thinking and tireless.Teachers through continuous learning, observing, thinking, feeling, experience, the teaching interactive deep structure of three levels has a profound understanding and the understanding, thus make the meaning of teaching interactive communication more rich and deep.

\subsection{Keenly aware, the flexibility to create: the natural organic to communicate meaning}

The significance of interactive communication is the natural flow of the dialogue between teachers and students is linked together, the natural organic process, rather than divided the process of jumping, far-fetched.This requires teachers to respond to events in the interaction of teaching and students maintain a high level of sensitivity, and gradually formed the teachers' creative wisdom. The teacher wants to flexible response to the formation of students, to gather and capture of students' information feedback, on the water education timely inspiration. Students.Keen awareness from the teachers listen to and respect for students.A don't respect students, the students as a specific individual teachers don't really listen to the students, also won't detect the thoughts of 
students, his heart only oneself and teaching point of view.Even if students have some rich, different views, or the students' classroom performance of unexpected change, teacher would turn a blind eye, even when this interactive teaching of "noise".

\section{Summary}

Keenly aware of teachers, the flexibility to create, make the meaning of the interaction of teaching communication nature fluent, one integrated mass.It needs teachers upfront design, but is more meaningful communication between teachers and students of natural, rather than a teacher to student's deliberately forced.On the one hand, it requires that the teachers and students both sides with a positive attitude seriously into teaching interaction;On the other hand, it also need to each party according to the other party's response to generate the following teaching.Teachers teaching is next generation, for students to learn thinking of nature, is based on the further extension of students to raise questions. To the distinction between the teaching interactive surface structure and deep structure and surface structure is beneficial to teachers in teaching interaction on the basis of further understanding the deep structure of the teaching interaction, understanding the characteristics of the teaching interactive significance in communication and for their own requirements, so as to improve teachers' teaching interactive state, in the spiritual life growth in interactive teaching between teachers and students fully implementation.

\section{References}

[1] ZHENG Hang sheng, WEI Jinsheng. Main schools of modern western philosophy [M]. Beijing: Chinese people university press,1988: 325.

[2] Feng Zhong liang, WU Xin chun, YAO Hai lin, WANG Jianmin. Education psychology [M]. Beijing: people's education press,2010.

[3] Qin Guangtao. Meaning world [M]. Changchun: jilin education press,1998: preface of the book.

[4] Wang Yichuan. Experience and generate: the experience meaning of western aesthetic [J]. Research of literature and art 1988(3): 130-147.

[5] Jaspers. What is education [M]. ZHOU Jin translate.Beijing: life, reading, new knowledge,1991: 4.

[6] WAGN Tian-yi, XIA Zhi lian, ZHU Mei yu. Foreign educational history[M].The revised edition. Beijing: Beijing normal university press,1993: 320.

[7] ZHU Xiao-hong. To understand the teacher's love: based on the emotional phenomenology horizon schere [J]. Education Research,2009(11): 53-57.

[8] ZHU Guang-ming. The exploration of phenomenological pedagogy idea of Fan Mei nan [J]. Journal of comparative education research.2005(4): 15-20. 